\title{
¿QUÉ ES LA BIOÉTICA?
}

\section{Ana Rodríguez Allen}

En los últimos meses no ha pasado un día en el que los medios de comunicación masiva, sobre todo la prensa escrita, hayan dejado de publicar alguna noticia referente a problemas de orden biomédico, es decir, en relación con todo lo que atañe al campo de la salud como: medicamentos, investigaciones clínicas con humanos, fecundación in vitro, esterilizaciones o privatización de los servicios de salud, etc. Las noticias no se han limitado a presentar los casos sólo desde un punto de vista meramente divulgativo, sino que además han subrayado la necesidad de discutir el asunto desde la ética. En efecto, problemas como el suscitado por el fallo de la Sala Constitucional que prohíbe la fecundación in vitro, ${ }^{1}$ no sólo pone en entredicho los renombrados "valores tradicionales de la sociedad costarricense", como el "diálogo al

1. Tomando como base en el artículo 21 de la Constitución Política de la República que dice: "La vida humana es inviolable", algunos de los magistrados consideraron que el concepto de vida humana debía interpretarse como la unión del ovulo y el espermatozoide desde su concepción, y es partir de dicha interpretación que consideraron que la fecundación in vitro contravenía las normas jurídicas establecidas en la Constitución. 
estilo costarricense", sino que además invita a polemizar sobre el tema. En el sentido de un debate abierto de ideas y bien argumentado acerca de las interrogantes que suscita la biotecnología sobre todo para que los ciudadanos construyan sus propios criterios.

Como veremos en este ensayo, la decisión de la Sala Constitucional sobre la fertilización in vitro fue la chispa que despertó a la ciudadanía, acerca de lo que es correcto y lo que no lo es en el campo biomédico y puso al descubierto tendencias en esta discusión. En el caso de la prensa nacional se mostró sólo una visión, la de la ética paternalista médica. Y sobre todo se empezó a hablar de un nuevo campo del conocimiento llamado bioética; pero una bioética con matiz costarricense, que dejaba al margen la bioética crítica, cuyo planteamiento muestra una novedosa visión que sacude el paradigma tradicional de la medicina clásica.

Desde hace mucho tiempo, en varios países se han nombrado Comités de bioética nacionales integrados por miembros de la comunidad y representantes de todas las tendencias y disciplinas, que se han dado a la tarea de afrontar las cuestiones éticas y jurídicas que ha implicado el desarrollo de la biomedicina y la biotecnología para la sociedad y en particular se han abocado a la labor de informar a la ciudadanía de las consecuencias de este desarrollo y de la toma de una u otra decisión en el debate acerca de la salud para el futuro. Éste sin embargo no ha sido el caso de Costa Rica y por eso podemos advertir cómo los ciudadanos se preguntan y discuten sobre temas éticos, a pesar de que no han podido acceder a la información necesaria.

Para poner un ejemplo claro, en el mundo anglosajón, la discusión en torno a los problemas que plantea la bioética tienen ya treinta años, por ello podemos encontrar una amplia 
y variada bibliografía con diferentes puntos de vista acerca de problemas como: la curación de enfermedades a través de la manipulación de embriones, "la maternidad de alquiler", el derecho a morir, el paternalismo duro y la autonomía del paciente, la escasez de recursos sanitarios, el consentimiento informado, etc.

En relación con lo anterior, las reflexiones de filósof@s morales difieren de una u otra postura al respecto de si la bioética es un campo que compete a una teoría moral filosófica o si pertenece a otro campo. Precisamente esta discusión nos muestra que no existen fronteras disciplinarias en lo que concierne a problemas sociales, lo que existen son problemas cuya resolución es urgente. Y por esta razón es difícil delimitar el objeto de estudio de la bioética. Lo que si parece estar claro es que la bioética intenta subsanar una necesidad cada vez más acuciante en el campo de la biomedicina que la ética tradicional médica ya no cumple, que consiste en tomar decisiones justas y operativas en situaciones de conflicto de valores. Por eso, cada vez más, en los países en donde operan Comités de bioética, la toma de decisiones en el campo de la salud no recae en una o en un grupúsculo de personas de una misma disciplina. La idea es promover la participación creciente de $1 @$ s ciudadan@s en las decisiones que les afectan.

Pero hay una cuestión fundamental en lo que concierne al campo de estudio de la bioética que es confuso y por ello, es inevitablemente importante que la aclaremos. Aunque el origen mismo de la transdisciplina ha hecho discutir con valiosos argumentos a estudiosos de la ética como Singer, Kuhse o Berlinguer ${ }^{2}$, todo esto ha generado un encendido

2. Cf. KUHSE, H, SINGER, P. et al. Bioethics. An Anthology. Oxford: Blackwell Publishers Inc, 2001. Y BERLINGUER, G. Ética della salute. Milano: Il sagiatore, 1997. 
debate que aún no acaba. Algunos autores sostienen que la bioética surgió con las experimentaciones nazis en los campos de concentración en los años cuarentas y a las sucesivas reflexiones morales que generó el Proceso de Nüremberg. Otros encuentran sus orígenes en los años cincuentas y sesentas con el espectacular desarrollo y las grandes innovaciones de la biomedicina y la genética molecular; transformaciones que se llevaron a la práctica médica en los Estados Unidos.

Para el filósofo de la ciencia y bioeticista, Fermind Roland Schramm de la Escuela Nacional de Salud Pública de Río de Janeiro, hay dos etapas en el desarrollo de la bioética. La primera etapa empieza en los años setentas y surge de los movimientos culturales de la época como el feminista, que ya en ese entonces abogaba por el derecho de las mujeres a decidir acerca de sus cuerpos y no aceptaban ningún sometimiento a una política de salud paternalista que invalida los principios básicos de la bioética: la autonomía y la justicia ${ }^{3}$. Para éstas una teoría polííca diseñada bajo "el modelo paternalista duro" es la que elabora estrategias políticas para "beneficiar" al pueblo; pero realizadas sin ninguna participación popular y sin su consentimiento. En este período explica Roland que la discusión giraba en torno: "si la bioética es una disciplina científica of filosófica" ${ }^{4}$ ó que las

3. Cf. BOLADERAS, Margarita. Bioética. Madrid: Editorial Síntesis, 1998, p. 44. En esta obra define la autonomía y la justicia: Respeto a la voluntad y a las decisiones sobre la forma de vivir y de morir de cada persona; dar información y el apoyo necesario para que las personas puedan decidir con conocimiento de causa sobre aquellas cuestiones que afectan a su salud, su vida y su muerte; procurar un trato no discriminatorio, sean cuales sean las caracteristicas del sujeto atendido; Emplear los recursos humanos y económicos proporcionados al caso concreto y a la situación general: Trabajar a favor de una distribución adecuada de los recursos en los distintos niveles de decisión presupruestaria.

4. ROLAND SCHRAMM, Fermin. Nuevas tendencias en bioética: la bioécica global de Van Rensselaer Potter. En: Cuademos del programa regional de bioctica. Editorial Organización Panamericana de la Salud. N² 4, 14 p., 1997. 
cuestiones que planteaba la bioética no eran nuevas, sino que ya se venían discutiendo en ética aplicada.

Para el médico oncólogo Van Ressenlaer Potter, el padre del neologismo, la tarea era clara; en los años setentas definía la bioética como una ciencia de la sobrevivencia en el sentido ecológico. Con ello, Potter pretendía construir una ética científica ecológica que por un lado, nos pusiera alerta del posible desarrollo sin control de la biotecnología y por otro, un saber que era necesario aprovechar no sólo en biomedicina sino en otros campos. La bioética para Potter debía llegar a convertirse en una nueva ciencia de la vida, fundamentalmente interdisciplinaria, preocupada por la sobrevivencia de los seres vivos, por la preservación del medio ambiente y por la calidad de vida de los seres humanos.

La segunda etapa de la bioética, dice Roland, es la que surge con los dilemas que trae la globalización, pues los problemas que se van presentando resultan cada vez más complejos, debido a los adelantos en conocimientos y tecnología. Un ejemplo de ello es la manipulación genética de los alimentos, la clonación terapéutica o la investigación con embriones no utilizados en los procesos de fertilización in vitro o la esterilización, que plantea un análisis ético profundo del control genético de la población mundial y que nos obliga a buscar una visión más amplia de los problemas. Es así como, la bioética encuentra cabida en los círculos sanitarios, pues los conflictos morales surgidos a partir de la modificación genética de seres vivos tiene efectos en la calidad de vida y en los derechos de las personas que la ética tradicional médica no alcanza a resolver. En este sentido, para Roland la bioética es novedosa pues rompe con el paradigma ético-médico que la hacía "inseparable de la religión y de la tradición milenaria" ${ }^{5}$ y fundamentalmente porque es

5. Ibíd., $18 \mathrm{p}$. 
más operativa y más dinámica que el estudio" abstracto de las conductas morales" ${ }^{\prime \prime}$ propio de la filosofía.

Pero también, en las últimas dos décadas, el término bioética ha sido usado con múltiples significados y en relación con una serie muy amplia y diferenciada de cuestiones. Se han visto intervenciones de personas que incluyen en el ámbito de la bioética casi todo y por esta razón en las discusiones públicas el nombre bioética es usado sin ningún significado preciso. ${ }^{7}$ Pensemos, por ejemplo, en la definición de bioética de 1995 de la Encyclopedia of Bioethics cuya exposición afirma que dicho campo se ocupa del: "Estudio sistemático de la conducta humana en el campo de las ciencias biológicas y la atención en salud, en la medida en que esta conducta se examine a la luz de valores y principios morales" 8 . Definición bastante vaga, que como señala el filósofo Antonio Marlasca ${ }^{9}$ no aclara qué vamos a entender por valores y principios morales. Tal vez porque su ámbito de acción es muy amplio.

En Costa Rica, algunos pensadores y personas dedicadas al campo de la salud han llamado bioética a la ética tradicional médica, pues sospecho que para muchos integrantes de la vieja escuela era urgente hacerla encajar dentro de los principios del paradigma tradicional médico. Esto es lo que el científico Karl Popper llamaba un acto de "inmunización"; aunque sólo sea para parecer actualizados. Yo quiero

6. Ibid., $20 \mathrm{p}$.

7 Al respecto dice Eugenio Lecaldano, no es extraño escuchar en Italia eslóganes en contra de la bioética, que es necesario (...) liberarse de la bioética (...) 6 que la bioética es inmoral. Cf. LECALDANO, Eugenio. Bioética. Le scelte motali. RomaBari Gius Laterza y Figli Spa, 1999, p.4.

8. REICH, W.T. Encyclopedia of bioethics. London: Collier MacMilland, 1978, vol. I, p. XIX.

9. Cf. MARLASCA, Antonio. Introducción a la bioética. Heredia: Facultad de Filosofía y Letras, Universidad Nacional, 2001. 
ilustrar este punto con un simple ejemplo, en el artículo publicado en el diario La Nación del 11 de noviembre del 2000 , de Enrique Vargas Soto $^{10}$, se decía lo siguiente en relación con la fertilización in vitro y la bioética:

"Es el tema de estos días y de siempre. En general, se ha calificado el fallo de la Sala Constitucional que prohibe la fecundación in vitro como de corte religioso, lo que es $a b$ solutamente falso. No podía apartarse de la Constitución Política (artículo 21: "La vida humana es inviolable"), ni del dato objetivo y cierto para la interpretación de este precepto constitucional, expresado por la Caja Costarricense del Seguro Social, tan parca en esta materia y coincidente con el de la Procuraduría general de la República. Lo que sucede es que la información médica venía por una sola via, cientificista y favorable a la aplicación de técnicas sin condiciones y ampliada por algunos comunicadores y articulistas prejuiciados contra la Iglesia Católica. Se magnificó así ese poder médico unilateral y no se le había dado difusión a la otra vía: cuándo es realmente que comienza la vida humana.(...)

Se supone que quienes atacan a la Iglesia católica por su defensa de la vida desde el momento de la concepción no desconocen que en la Comisión Científica que asesora al Papa Juan Pablo II hay 21 científicos galardonados con el Premio Nobel. Sus exhortaciones no tienen otro interés que la defensa misma de la vida. La palabra de Juan Pablo II es clave: los hijos no son un derecho, sino un don de Dios. Porque somos receptores de vida. A nadie se dio la que tiene. (...)

10. VARGAS SOTO, Enrique. ¿Cuándo comienza la vida? Un fallo que protege y gura. Periódico La Nación. Sección: Opinión. Sábado 11 de noviembre del 2000, p. $15 \mathrm{~A}$ 
Mis felicitaciones a la Sala Constitucional por tutelar el derecho al valor absoluto de la vida desde su comienzo, conforme lo establece la Constitución Política. Su fallo no es una intromisión en los derechos de la persona, sino una protección y una guía esclarecedora para que el ejercicio de la medicina se encuadre dentro del campo de la bioé. tica (la negrita es mía) y no dentro de la vaguedad de una ciencia sin conciencia moral, sin límites, permisiva y a veces comercial".

Como vemos la visión ética en la que se inspira el autor tiene como base la concepción moral judeo-cristiana tradicional, que parte como veremos de unos principios determinados que poseen su propia coherencia interna. En este caso, el comentarista pone de manifiesto, el maridaje entre lo jurídico y lo religioso. Esto es lo que llama el bioeticista Diego Gracia, ética tradicional o Código único. Y además vemos cómo la decisión de los magistrados en torno al tema de la fertilización in vitro pone en entredicho, restringe y distorsiona la definición de la concepción de vida humana, so pretexto de que la vida es un bien protegido por la comunidad y las leyes. Pues como aclara Marlasca "(...) en el ámbito jurídico persona no es igual a ser humano o vida humana, sino que estrictamente suele entenderse al "ente capaz de derechos y obligaciones"11 Sin embargo, la responsabilidad del Estado en algo tan decisivo como la reproducción asistida se ha plasmado en prescripciones legales a través de la Sala Constitucional que no dejaron lugar a una discusión ampliada a diversos sectores de la sociedad civil costarricense. Valdrá la pena preguntarse si es justo, que todos los conflictos éticos de la biomedicina se resuelvan desde la pura y dura normatividad religiosa y milenaria. El problema de la fertilización

\footnotetext{
11. MARLASCA, Antonio. Introducción a la bioérica. Heredia: Facultad de Filosofía y Letras, 2001, p. 245
} 
in vitro en nuestro país no se resolvió como señala Vargas Soto desde el "campo de la bioética". Se resolvió desde la norma jurídico-cristiana sin posibilidad de revisarla desde una ética crítica. Yo creo que el comentarista confunde la deontología médica tradicional con la bioética de naturaleza más transdisciplinaria.

El artículo de Vargas Soto es ideal para ejemplificar cómo se concibe la relación entre religión, derecho y medicina en el orden patriarcal. En el ámbito de este pensamiento el profesor Diego Gracia encuentra que, así como la historia cristiana considera a Dios como el gobernante de los hombres en la Tierra; de igual forma el rey-filósofo es el gobernante en la polis, en el estado ideal de Platón. Y de este modo y por analogía, sucede lo mismo en la relación médico y paciente. El médico pasa a ser el soberano y guardián del cuerpo de $1 @$ s ciudadan@s. Así en su obra Procedimientos de decisión en ética clínica, Gracia indica:

"Pues bien, la ética médica clásica no se entiende más que considerando al médico como otro gobernante, responsable del cuerpo de sus pacientes y que como tal estaba obligado a exigirles el cumplimiento del Código Único moral en el ámbito concreto de su actividad profesional. Sin esto tampoco se explica el desarrollo histórico de la ética médica. El médico se ha visto clásicamente a sí mismo como un político, es decir, como el gobernante del cuerpo de sus pacientes. A imagen y semejanza de los otros dominios de gobierno, éste del médico fue claramente despótico (la negrita es mía). Quiere decir esto que el médico no consideró necesario tener en cuenta las opiniones de sus pacientes.(...)

El Código Único se ha expresado tradicionalmente en forma de leyes, preceptos o mandamientos. De ahi que el 
procedimiento de la Ética viniera a coincidir con el Derecho. En el orden de la ética religiosa, esto es evidente, como lo demuestra la conversión de la moral religiosa en Derecho Canónico, tanto en el mundo judío como en el árabe y el cristiano." 12

Este paternalismo autoritario tan reafirmado en los últimos días en la prensa nacional es defendido por Alberto di Mare en estos términos:

"Argumentos que no vienen al caso: se trata de mi cuerpo y sobre ello decido sólo yo; (...) el médico tiene el derecho a curar (es decir, a manipular) al paciente $y$ este debe someterse a lo que disponga su natural señor (la negrita es mía), único que está iluminado adecuadamente por la ciencia; el avance de la ciencia, es el fin último, que todo lo justifica". ${ }^{13}$

La práctica de la fecundación artificial pareció suscitar interrogantes éticas del todo nuevas relativas a los derechos y deberes de los ciudadanos en el país; pues en el momento en que salió a la luz el problema existía un vacío legal y lo correcto debió haber sido, de acuerdo con el procedimiento democrático, como indica Norberto Bobbio, buscar diferentes "(...) procedimientos para tomar las decisiones colectivas a través de un libre debate, que pueda dar lugar a una decisión o concordada o tomada por mayoría (...)"14 que es garantizar iguales consideraciones a todas las personas. El

12. GRACIA, Diego. Procedimientos de decisión en ética clínica. Madrid: Editorial EUDEMA, 1991, pp. 21-22.

13. DI MARE, Alberto. El respeto de la vida humana. El que tenga oídos que oiga. Periódico La Nación. Sección: Opinión. Lunes 20 de noviembre de 2000, p.15A. 14. BOBBIO, Norberto. Derecha e izquierda. Madrid: Editorial TAURUS, 1995, p.31. 
problema en relación con la fecundación artificial fue que un grupo reducido de personas se arrogó el derecho a decidir qué es lo mejor para todos sin un debate amplio. Pues, hasta ahora, las razones morales que se han esgrimido en la prensa nacional contra la procreación asistida se han centrado alrededor de qué es la vida. Y por eso resulta contrastante que luego del fallo de la Sala Constitucional en contra de la fertilización in vitro, el fallo popular no lo avalara:

"La mayoría de los costarricenses no están de acuerdo con el fallo de la Sala Constitucional que prohibió la fecundación in vitro (...). Un estudio de opinión de la empresa Demoscopía para La Nación evidencia que el $\mathbf{6 2 . 5}$ por ciento de los consultados rechaza la decisión de los magistrados (la negrita es mía); 32.3 por ciento la avalan y 5.2 por ciento no saben o no responden el asunto."15

Pero, hay más de fondo en este debate y me parece que no se ha tratado adecuadamente el tema, pues, son pocos los juristas en nuestro país que se han preocupado seriamente de los problemas relacionados con el perfeccionamiento de las nuevas técnicas médicas, es decir, del reconocimiento de los nuevos valores que surgen en este campo y frente a los cuales, el artículo 21 de nuestra Constitución se queda atrás. Algunos juristas deberían abocarse a buscar una respuesta adecuada a las exigencias que implican los avances técnicos en biomedicina. Es urgente promover una reflexión abierta acerca de la ciencia y la tecnología adecuada a las situaciones prácticas que se suscitan en el campo biomédico y que están haciendo tambalear las creencias de $1 @ s$ ciudadan@s. Porque las tesis hasta ahora planteadas son

15. MENDEZ GARITA, William. Tícos avalan fecundación in vitro. Revés a fallo de Sala IV que la prohibió. La Nación. Sección: El país. Lunes 23 de octubre de 2000, p.4A. 
dependientes de presupuestos ideológicos dirigidos a mostrar la peligrosidad de la biomedicina y generar ideas confusas acerca de la ciencia en la opinión pública.

Max Charlesworth, filósofo y bioeticista australiano, mantiene la tesis que al no existir un consenso público en relación con un conjunto de valores que surgen con el desarrollo biotecnológico, debería haber pluralidad de posturas éticas:

"En una sociedad liberal, cabe esperar que el valor de la autonomía personal fuera fundamental en el seno de los debates éticos sobre las técnicas nuevas de procreación y formatos nuevos de familias límites del tratamiento médico y si existe o no "el derecho a morir"; intervención genética en la vida humana, etc. También cabe esperar una clara distinción entre la moralidad de estos temas y su legalidad: si la ley debería intervenir o no en prohibirlos o controlarlos. Se podría pensar también que el pluralismo ético, particularmente en el campo de la tecnología de la reproducción, no sólo sería tolerado, sino recibido positivamente y fomentado. Sin embargo, lo que nos encontramos en la realidad es que muchas posiciones éticas propuestas en esta área están a menudo en conflicto con los valores que conforman la esencia de la sociedad liberal."16

Patrizia Borsellino en su libro Bioética tra autonomía e diritto, concibe la bioética como un terreno de confrontación y desencuentro entre lo moderno y lo posmoderno en donde coexisten diversos modos de entender y practicarla, como los diversos modos de entender la naturaleza ${ }^{17}$.

16. CHARLESWOTH, Max. La bioética en una sociedad liberal. Cambridge: University Press, 1996, pp.1, 2.

17. BORSELLINO, Patrizia. Bioética tra autonomía e dirtito. Milano: Editore Zadig, 1999, p.18. 
Actualmente, la bioética se concentra en los problemas microéticos y macroéticos que surgen del campo específico de la salud ${ }^{18}$. Al respecto Margarita Boladeras recopila y construye un concepto amplio para definirla:

1. "Comprende los conflictos relacionados con principios morales que surgen en todas las profesiones en salud, incluso en las profesiones "afines" y las vinculadas con la salud mental, así como las aplicaciones de la ciencia que afectan el curso de la vida.

2. Se aplica a las investigaciones biomédicas y sobre el comportamiento, independientemente de que influyan o no de forma directa en la terapéutica.

3. Aborda una amplia gama de cuestiones sociales, como las que se relacionan con la salud pública, la salud ocupacional e internacional y la ética del control político de la natalidad, entre otras.

4. Va más allá de la vida y la salud humana, en cuanto comprende cuestiones relativas a la vida de los animales y las plantas; por ejemplo, en lo que concierne a experimentos con animales y a demandas ambientales conflictivas." 19

En Costa Rica formé parte del primer Comité de bioética de la Caja Costarricense del Seguro Social que fungió de 1996 a 1998 y que se encontraba integrado en su mayoría por representantes del área de la biomedicina, un representante religioso y la suscrita como representante de la comunidad. El objetivo del Comité en sus inicios era crear un clima de discusión en torno a temas relativos a ética de la

18. Para los biceticistas existen dos tipos de ética en el campo de la salud. La macroética que surge a partir de las preguntas que se plantean los que se proponen políticas de salud alrededor de la distribución de recursos, los modelos organizativos, las investigaciones clínicas, etc. Y la microética que está relacionada con las prácticas curativas. La primera está relacionada con la medicina preventiva y la segunda con la medicina curativa.

19. BOLADERAS CUCURELLA, Margarita. Bioerica. Madrid: Editorial Síntesis, 1998, p. 9 . 
salud desde una visión interdisciplinaria. La primera dificultad que enfrentó dicho Comité, consistió en que los encargados de elaborar directrices en salud consideraban que sus Comités Científicos o Consejos de Investigación ya contemplaban componentes éticos; pero ética profesional médica ${ }^{20}$. Sin embargo, la propuesta del Comité de bioética sí era novedosa por lo menos en dos aspectos: en primer lugar, el interés de la mayoría de los miembros del Comité era educar a los profesionales sanitarios en una concepción ética que no siguiera los lineamientos del viejo paradigma de la ética tradicional médica, es decir, que la toma de decisiones en materia de salud complejas no podía seguir recayendo en un grupo reducido de personas con una visión unidisciplinar, la medicina y en segundo lugar, que era necesario propiciar una ética del diálogo y de la comunicación en contraposición como expresa Borsellino a una ética del fanatismo o de la propaganda y el adoctrinamiento. Y sobre todo abriéndole a 1@s ciudadan@s, usuari@s de la salud, la posibilidad de aprender, conocer y decidir sin ningún tipo de coacción acerca de la salud de sus cuerpos. Pero, esto no fue así, en 1998 se despidió al grupo con argumentos burocráticos.

Para finalizar, no creo que se puedan tomar decisiones éticas, ni hablar de derechos, si los ciudadanos no están bien informados y formados alrededor de los hechos relevantes en este campo, lo único que podemos alcanzar es caer en una especie de minimalismo informativo, propio de sociedades autocráticas.

20. Al respecto Marlasca afirma: "Normalmente se considera que un profesional satisface adecuadamente las exigencias éticas de su profesión si observa cuidadosamente las normas contenidas en el código de ética del colegio profesional respectivo. Estas normas, por lo general, se reducen a lo siguiente: guardar fidelidad a la institución o al patrón que suministra trabajo; ser respetuoso con los superiores; Evitar la competencia desleal entre los colegas; No cobrar por debajo de ciertas tarifas mínimas; Manienerse al día en lo que respecta a los conocimientos propios de la profesión; no aprovecharse de la situación de superioridad para engañar o manipular a los clientes; guardar el secreto profesional; Defender los intereses -sobre todo económicos- de los profesionales colegiados, etc." Cf. MARLASCA, Antonio. Intraducción a la écica. San José, C.R. EUNED, 1997, p.52. 